УДК 336

\title{
КОНЦЕПТУАЛЬНАЯ МОДЕЛЬ УПРАВЛЕНИЯ ПРОМЫШЛЕННЫМИ ПРОЕКТАМИ В ХОЛДИНГОВОЙ КОМПАНИИ
}

\author{
(C) 2013 г. А. Г. Бадалова, И. В. Дмитров
}

Московский государственный технологический университет «СТАНКИН»

В статье представлена концептуальная модель управления промышленными проектами в холдиновой компании, подробно рассматриваются все семь блоков модели и составляющие их элементы.

Ключевые слова: промышленные проекты; управление; конщептуальная модель; холдинговая компания.

The article presents a conceptual model of the industrial project management for the holding company. All the seven blocks of the model and their constituent elements are discussed in details.

Key words: industrial projects; management; conceptual model; a holding company.

Признание стоимостной концепции управления в качестве доминирующей при управлении холдинговыми компаниями существенно меняет подход к управлению и организации управления промышленными проектами (ПП) в рамках стратегического развития холдинговой компании, а также предопределяет требования к разработке организационно-экономического механизма управления ПП в холдингах [1].

С другой стороны, возможные способы реализации стратегии развития холдинговых компаний (с позиций стоимостной концепции) заставляют по-иному:

- осмысливать процессы планирования и реализации ПП, бизнес-процессы управления ПП;

- проводить оценку рейтингов и выбирать наиболее значимые ПП;

- оценивать качество управления и эффективность реализации ПП с позиции создание долгосрочных устойчивых конкурентных преимуществ холдинга и увеличения стоимости бизнеса.

В связи с вышеуказанным, достаточно важной и актуальной научно-практической задачей, от успешного решения которой зависит возможность разработки организационно-экономического механизма управления
ПП (ОЭМУПП) в холдинговой компании, является разработка концептуальной модели.

Прежде чем разработать и рассмотреть основные компоненты концептуальной модели управления ПП необходимо определиться с понятием организационно-экономического механизма. Следует отметить, что в настоящее время у специалистов - теоретиков и практиков отсутствует единое понимание и, соответственно, общепринятое определение организационно-экономического механизма.

Исходя из поставленной цели и задач проводимого исследования и в соответствии с рекомендациями стандарта РМВОК [2] под организационно-экономическим механизмом управления промышленными проектами в холдинговой компании будем понимать систему управления ПП, учитывающую организационные особенности холдинга, экономику бизнес-процессов, ресурсные границы и инструменты управления ПП, а также риски и финансовые последствия управления ПП для холдинговой компании.

При этом под промышленными проектами понимаются проекты, осуществляемые холдинговой компанией, направленные на развитие бизнеса за счет освоения новых рынков и выпуска новых продуктов, требующие существенных инвестиций и позволяю- 
щие существенно снижать текущие затраты за счет применения новых инновационных технологий.

Предлагаемая концептуальная модель управления ПП в холдинге приведена на рис. 1. Исходя из представленной модели следует, что изначальным первым блоком, «входом» модели, определяющим остальные, последовательно следующие друг за другом от общего к более частному, является определение стратегии развития холдинговой компании в целях управления стоимостью бизнеса. Задача классификации возможных стратегий развития холдинговых компаний и разработка инструментов обоснования выбора наиболее адекватной из них является актуальной научно-практической задачей, требующей для решения специального исследования, и в рамках данной работы не рассматривается.

Среди методов влияния на стоимость бизнеса в настоящее время специалисты отмечают финансовые, маркетинговые и организационные. Для реализации каждого из указанных методов целесообразно отметить следующие наиболее значимые инструменты:

— финансовые методы: увеличение объемов продаж; управление величиной операционной маржи; инвестиционный менеджмент; управление денежными потоками; объем денежных потоков; сроки возникновения притоков и оттоков денежных средств; управление рисками;

- маркетинговые методы: выбор и анализ рынка; брэнд-менеджмент; управление конкурентными преимуществами товара; связи с общественностью; управление стратегическими отношениями;

- организационные методы: развитие навыков и умений персонала организации; системное управление компанией; отношение к лидерству внутри компании; системы мотивации персонала.

Стратегическое развитие холдинговой компании непосредственно связано с созданием добавленной стоимости, способами достижения которого являются:

1) создание новых отраслей, т. е. постоянный поиск компанией свободных рыночных ниш и формирование в них новых отрасли;

2) заключение рыночных сделок, связан- ное с тем, что компания опережает других участников рынка благодаря хорошим навыкам выявления потенциальных сделок с их последующим осуществлением;

3) распределение ограниченных ресурсов, при котором компания эффективно распределяет капитал, денежные средства, временные и информационные ресурсы, а также кадры по бизнес-подразделениям;

4) распространение ценных навыков, связанное с непрерывным распространением наиболее ценных умений и навыков в бизнесподразделениях;

5) развитие имеющихся у сотрудников холдинговой компании талантов предполагает непрерывный процесс привлечения, сохранения и развития талантливых кадров, которой ставится на организационную основу;

6) одновременное инновационное развитие разных направлений бизнеса, связанное с демонстрацией компанией устойчивого превосходства в инновационной деятельности по нескольким направлениям бизнеса одновременно.

Систематизация и обобщение указанных методов и инструментов управления стоимостью, а также способов создания добавленной стоимости холдинговой компании в целях проводимого исследования позволяет выделить три базовых способа реализации возможной стратегии развития холдинга, указанных во втором блоке концептуальной модели.

Первый способ - система операционных улучшений бизнеса, имеющих достаточно локальный характер, направленных прежде всего на снижение/управление затратами, и не требующих инвестиционных управленческих решений. Указанный способ не предусматривает ни инвестиционных, ни тем более, реализации промышленных проектов.

Второй из выделенных способов связан с развитием бизнеса за счет приобретения профильных активов и/или увеличение доли профильного рынка. Реализация данного способа предполагает приобретения активов уже существующих компаний/предприятий, реализации наиболее эффективных (с позиции управления стоимостью бизнеса) форм реорганизации компании - слияние и присоединение.

Рассмотренные способы представляет 
1. Определение стратегии развития холдинговой компании в целях управления стоимостью бизнеса

\section{2. Выбор способа и формы реализации стратегии развития холдинга}

Система операционных улучшений бизнеса
Развитие бизнеса за счет приобретения профильных активов и/или увеличение доли профильного рынка
Развитие бизнеса за счет освоения новых рынков и выпуска новых продуктов

\section{3. Определение агрегированных объектов и базовых задач управления развитием} холдинга

Формирование порт-феля ПП / проектно-го портфеля
Реализация базовых задач управления обоснованно отобранными ПП

\section{4. Декомпозиция процесса управления промышленными проектами}

\begin{tabular}{|l|l|}
\hline $\begin{array}{l}\text { По уровням управления } \\
\text { (стратегическому, тактическому, } \\
\text { оперативному) }\end{array} \longleftrightarrow \begin{array}{l}\text { По бизнеспроцессам (основным } \\
\text { и вспомогательным) }\end{array}$ \\
\hline
\end{tabular}

\section{5. Оценка качества управления и результатов реализации ПП}

\begin{tabular}{|c|c|c|c|}
\hline $\begin{array}{l}\text { Формирование } \\
\text { совокупности } \\
\text { задач по этапам } \\
\text { планирования ПП }\end{array}$ & $\begin{array}{l}\text { Разработка } \\
\text { критериев } \\
\text { и процедуры } \\
\text { оценки } \\
\text { рейтингов ПП }\end{array}$ & $\begin{array}{l}\text { Формирование } \\
\text { совокупности } \\
\text { критериев и } \\
\text { определение } \\
\text { условий реализации } \\
\text { ПП }\end{array}$ & $\begin{array}{l}\text { Формирование } \\
\text { инструментов } \\
\text { мониторинга } \\
\text { и управления } \\
\text { рисками } \\
\text { реализации ПП }\end{array}$ \\
\hline & $\begin{array}{l}\frac{1}{\gamma} \\
\text { овление } \\
\text { нгов ПП }\end{array}$ & 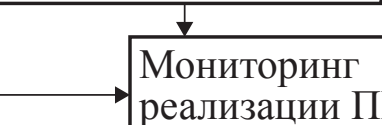 & $\downarrow$ \\
\hline
\end{tabular}

$\downarrow$

6. Выбор частных объектов, инструментов и форм организации управления эффективной реализации ПП

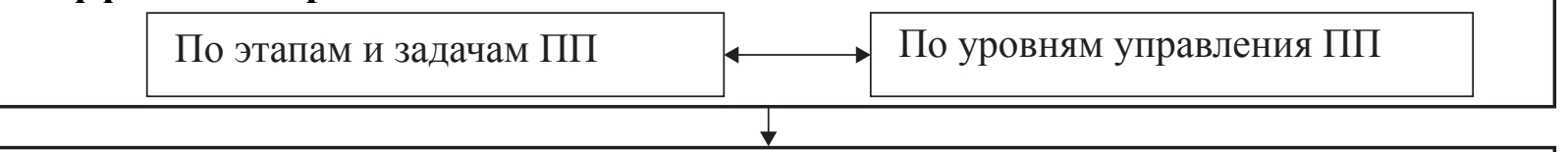

\section{7. Результаты управления ПП в холдинговой компании}

\begin{tabular}{|c|c|}
\hline $\begin{array}{l}\text { Формирование } \\
\text { сбалансированно- } \\
\text { го портфеля ПП }\end{array}$ & $\mid \begin{array}{l}\text { Повышение качества управления } \\
\text { ПП и достижение запланированных } \\
\text { результатов реализации ПП }\end{array}$ \\
\hline
\end{tabular}

Реализация принятой стратегии развития холдинга

Создание долгосрочных устойчивых

$\rightarrow$ конкурентных преимуществ холдинга Повышение стоимости бизнеса

Рис. 1. Концептуальная модель управления промышленными проектами в холдинговой компании 
интерес с позиции разработки концептуальной модели, но не является предметом проводимых исследований, прежде всего потому, что не сопряжены с разработкой и реализацией ПП.

Последним, третьим, способом реализации стратегии развития холдинговой компании является развитие бизнеса за счет освоения новых рынков и выпуска новых продуктов. Именно данный способ предусматривает принятие инвестиционных решений, связанных с оценкой рейтингов ПП, формирования сбалансированного портфеля ПП, планированием и реализацией ПП. Выбор и использование рассматриваемого способа реализации стратегии развития холдинга в качестве предметной области проводимого исследования, а также достигнутый уровень решения указанной научной проблемы предопределяют необходимость разработки ОЭМУПП.

Комментируя третий блок, остановимся лишь на базовых задачах управления ПП, поскольку остальные элементы очевидны, понятны и не требуют дополнительного пояснения. Как известно, традиционными базовыми задачами управления, независимо от объекта управления, являются: анализ и синтез, планирование, организация, учет и контроль, мотивация. Признавая равную значимость каждой из задач для реализации процесса управления, в рамках проводимого исследования в качестве основополагающей функциональной задачи управления ПП в холдинговой компании, от реализации которой напрямую зависит качество управления и результаты реализации ПП, принято планирование.

Именно поэтому при разработке инструментария оценки и повышения качества управления и результатов реализации ПП, укрупненной указанном в пятом блоке концептуальной модели, изначально формируется совокупность задач по этапам планирования ПП. Целенаправленное системное управление ПП холдинговой компании невозможно без рейтингования и мониторинга реализации ПП, инструментарий которых разрабатывается в рамках задач по этапам планирования ПП.

Конкретизация объектов управления и реализация принципов системности и комплексности управления предопределяет необходимость на основе агрегированных объектов и задач управления осуществить декомпозицию процессов управления ПП по трем традиционно выделяемым уровням управления (стратегическому, тактическому и оперативному) в пределах основных и вспомогательных бизнес-процессов. Данный вопрос отражен в четвертом блоке концептуальной модели.

Эффективное и непрерывное управление ПП в холдинге невозможно без рациональной организации процесса управления. Поэтому в шестом блоке предлагаемой концептуальной модели решается комплекс задач организации управления ПП, а именно выбор частных объектов, методов, инструментов и форм организации. При этом с учетом реализации принципа непрерывности и комплексности выбор должен осуществлять по этапам реализации и уровням управления ПП.

Завершающим седьмым блоком рассматриваемой модели выступает результирующий блок, определяющий результаты управления ПП — создание долгосрочных устойчивых конкурентных преимуществ холдинга и, в итоге, повышение стоимости бизнеса. Данный блок рассматривается как «выход» рассматриваемой модели, поэтому указанные составляющие его элементы не требуют дополнительного детального разъяснения.

Отличительной особенностью разрабатываемой модели является возможность определения всего перечня управленческого инструментария, разработка или применение которого необходимы для осуществления целенаправленного, системного, комплексного и непрерывного управления промышленными проектами в холдинговых компаниях.

В заключении отметим, что при разработке концептуальной модели управления ПП в холдинговой компании, а также при разработке ОЭМУПП использовались такие основополагающие принципы менеджмента как: целенаправленность, системность, комплексность и непрерывность. Принцип непрерывности, в частности, реализуется в первом блоке разработанной модели, поскольку в качестве цели управления рассматривается повышение (управление) стоимостью бизнеса. Системность и комплексность при реализации третьего, четвертого и пятого блоков, а 
непрерывность, прежде всего, в организационном шестом блоке.

Таким образом, предлагаемая концептуальная модель управления ПП позволяет не только определить совокупность управленческого инструментария, требующего разработки и апробирования в целях реализации стратегии развития холдинга и управления стоимостью бизнеса, но и является методологической основой для дальнейшей разработки ОЭМУПП в холдинговых компаниях.
Литература

1. Стратегическое управление инновационно-ориентированным развитием промышленных предприятий. / Под ред. А. Г. Бадаловой и М. Е. Просвириной. - М.: ФГБОУ ВПО МГТУ «СТАНКИН», 2012. - 109 с.

2. Руководство к Своду знаний по управлению проектами (руководство РМВОК). Изд. 4-е. - М.: Project Management Institute, Inc., 2009.

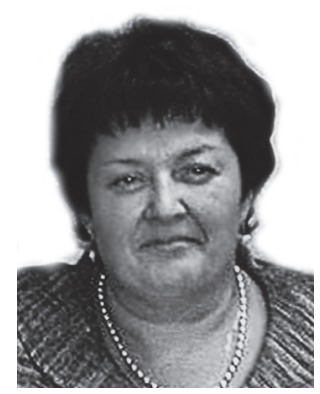

Анна Георгиевна Бадалова - профессор, д.э.н., заведующий кафедрой «Производственный менеджмент» Московского государственного технологического университета «Станкин».

Anna Georgievna Badalova - professor, Ph.D, Doctor of Economics, head of the Moscow State University of Technics «Stankin» «Production Management» department.

127006, г. Москва, ул. Краснопролетарская, д. 9, кв. 381

9 Krasnoproletarskaya st., app. 381, 127006, Moscow, Russia

Тел.: +7 (903) 582-29-73; e-mail: abadalova@mail.ru

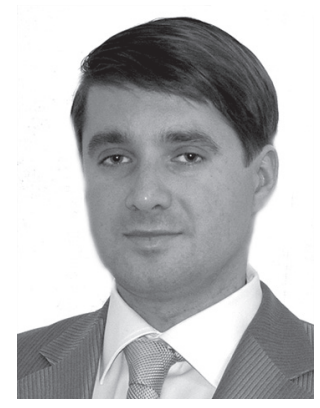

Илья Валерьевич Дмитров - соискатель кафедры «Производственный менеджмент» Московского государственного технологического университета «Станкин». Директор инвестиционной программы ООО «ЕвразХолдинг».

Ilya Valerievich Dmitrov - competitor for Candidate's degree of the Moscow State University of Technics «Stankin» «Production Management» department. Director of the «EvrazHolding» public corporation's investment program.

127562, Москва, ул. Санникова, д. 9, корп. 1, кв. 152

9 Sannikova st., bld. 1, app. 152, 127562, Moscow, Russia

Тел.: +7 (903) 79287 93; e-mail: div152@mail.ru 